\title{
Peertechz
}

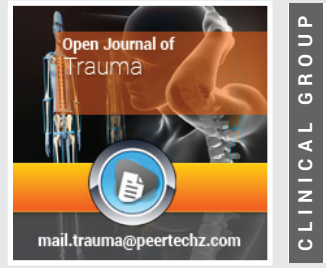

\section{Olle Bunketorp*}

Consultant, Orthopaedic Surgery, Sahlgrenska University Hospital, Sweden

Dates: Received: 17 March, 2017; Accepted: 13 June, 2017; Published: 14 June, 2017

*Corresponding author: Olle Bunketorp, Associate Professor, Department of Orthopaedics, Institute of Clinical Sciences, Sahlgrenska Academy, University of Gothenburg, Sweden, E-mail: bunketorp@hotmail.com

https://www.peertechz.com

\section{Introduction}

Whiplash Associated Disorders (WAD) have caused frustrating problems since decades for people injured in various types of accidents. Certain circumstances and misunderstandings explain this anomaly. They often become obvious (some as paradoxes) when it comes to estimation of crash severity, biomechanics, injury tolerance, diagnostic procedures, pain physiology, follow-up procedures and injury compensation. This presentation aims to describe some of them, especially with regard to the question of causality, i.e. if it is right to claim that an individual's posttraumatic problems are caused by a traumatic event or not.

There are well-defined criteria, which should be used to assess whether there is a causal link between a harmful event and a consequent disorder. They were presented by Sir Austin Bradford Hill, already in 1965 [1]. There have been several discussions on their validity since then [2]. Freeman et al., made a thorough review of the literature regarding these items in 2008 and 2009 [3,4]. The second paper gave specific reference to symptomatic spinal disk injury following motor vehicle trauma.

The first and second main criteria are related and dividable. The first criterion can be subdivided in three parts, and the second one in two.

1. There must be a plausible or possible relationship between exposure and effect (outcome). The central issue is whether a biomechanical violence may cause some biological damage. To determine this, one must assess the following elements:

a) the possibility for an injury to occur,

b) the sensitivity of diagnostic methods,

c) the possibility for the injury to cause the actual symptoms.
2. There must be a temporal relationship between exposure and outcome. To determine this, one must make judgements that refer to:

a) the time interval between the accident and the symptom appearance,

b) Variation of symptoms with time.

3. There must not be a more likely other explanations for the symptoms.

There is enough evidence to fully accept causality between the accident and the residual symptoms if all these three main criteria are fulfilled. However, the knowledge of many is still insufficient to understand how this should be done.

\section{The possibility for an injury to occur}

Several studies have tried to define the lower limit of crash severity, below which injury cannot occur. Most of them have included healthy volunteers in experimental tests, simulating a car occupant sitting face forward in a rear-end impact. The crash severity was usually expressed as the change of velocity $(\Delta \mathrm{v})$. The $\Delta \mathrm{v}$ limit for injury has been stated to be about $10-15 \mathrm{~km} / \mathrm{h}$ [5]. There are several reasons why such experiments cannot be used to establish injury thresholds. The first is logical: it is not possible to define thresholds for zero risk. Another reason is that people injured in real car crashes usually are more vulnerable than those taking part in various experimental tests. Car occupants' sitting postures are seldom perfect, so they are often exposed to asymmetric loads. Furthermore, factors like degenerative changes increase the vulnerability according to several studies [6-10].

It is difficult to make long-term follow-up of degenerative processes in controlled studies. That degeneration can be accelerated after a whiplash trauma has been shown in a study by Watkinson et al. [11] and by Hamer et al. [12]. In addition, it has been shown that approximately one third of patients with chronic neck pain have a previous neck trauma in their history $[13,14]$.

Few studies have been made on whiplash trauma in real accidents. One of them, a Swedish study from Folksam 
[15], included 236 car occupants in vehicles equipped with accelerometers, which gives a more reliable estimate of the crash severity than $\Delta \mathrm{v}$. The risk of sustaining WAD, lasting over one month, was estimated for three crash severities (described as mean acceleration or $\Delta \mathrm{v}$ ). The risk was $90 \%$ at $7 \mathrm{~g}$ or $27 \mathrm{~km} / \mathrm{h}, 20 \%$ at $5 \mathrm{~g}$ or $20 \mathrm{~km} / \mathrm{h}$, and $1 \%$ at $3 \mathrm{~g}(\Delta \mathrm{v}$ not presented). Another Swedish study showed that six percent of previous healthy occupant suffered from non-minor neck problems one year after a rear-end impact with $\Delta \mathrm{v}$ less or equal to $10 \mathrm{~km} / \mathrm{h}[9]$.

There are some circumstances that often lead to misunderstandings when the injury risk is estimated. The risk is usually judged from the visible material damage of the vehicle. In fact, there is a reverse relation between these entities for some crashes; the greater the damage, the smaller the risk. This paradox follows from the laws of mechanics. A car, which is hit by another car, changes velocity. The change of velocity is related to the transferred energy. The energy that is not absorbed by the car might hurt an occupant. The total crash energy is divided in two parts (at least): kinetic energy, accelerating the car, and mechanical energy, deforming the car. Let us imagine two scenarios: the first one where the impact hits the car's stiff structures, like the bumper or the tow bar; and the second one where the impact hits more ductile structures, like the sheet. The injury risk is greater in the first scenario, all other factors being equal. This rule is valid for all types of impacts, but especially for rear-end impacts, as the seat back acts like a catapult in those cases, which increases the forward acceleration of its occupant.

\section{The sensitivity of diagnostic methods}

Neck injuries are usually investigated radiologically, i.e. with plain radiographs or computed tomography (CT). Magnetic resonance imaging (MRI) is used for some cases. All have some limitations. A combination of all three methods increases the sensitivity and the specificity, but this is used only in selected cases.

Ordinary radiography has been the first choice since a long time when looking for fractures or subluxations/dislocations. It also gives quite a good overview. However, cervical fractures are not detected in plain radiographs in about half of the cases, according to a literature review by Holmes \& Akkinepalli [16].

Further, injuries to intervertebral disks, facet joints and ligaments are not visible on plain radiographs. The great difficulty to diagnose injuries to the cervical spine was demonstrated in a study on cervical specimens after road traffic fatalities [17]. Only 4 of 245 injuries (1.6\%), visible on surface cryoplaning microtomy, were identified on plain radiographs. The difficulty to diagnose injuries to the cervical zygapophysial joints and the intervertebral discs was verified in a literature review by Urenholt et al., [18]. Two of the studies made it possible to estimate the likelihood to detect cervical spine injuries using plain radiography. None of the lesions found at autopsy were identified at postmortem radiography in 16 patients examined by Taylor and Twomey [19]. Postmortem radiologic examination failed to detect 199 (64\%) of 309 lesions visible in the sectioned specimens of 58 patients, and a total of $93.5 \%$ of the minor lesions (mainly rim lesions and facet hemarthrosis) were missed according to Taylor \& Taylor [20].

\section{The possibility for the injury to cause the actual symp- toms}

The appearance, development, and duration of injury symptoms vary. Most injuries heal completely without sequelae, some do not. Injuries to vulnerable structures, like joints, may cause prolonged or lifelong symptoms. Injury symptoms most often decline gradually. The vast majority of injured subjects will experience a maximum of problems during a limited time period. In most cases, the symptoms decrease after a while, and finally they vanish or remain at a constant level. This pattern has been called the "Traumatic Principle" in Sweden. A recovery that deviates from this pattern has often been taken as a proof for an underlying medical condition that was not manifested before the accident, and that this condition has caused the deterioration, and not an injury.

There are several exceptions from the "Traumatic principle". Increasing problems, due to cartilage degeneration, caused by a knee ligament injury years before, is best known. It was presented as a typical exception by the Scientific Committee of the National Board of Health and Welfare in Sweden in 2006 [21]. The Committee also noted that the amount of energy that is required to damage a knee ligament is significant. However, the Committee did not make any remarks on the amount of energy, which is necessary to cause a spinal ligament injury.

In fact, also the development of WAD can deviate from the "Traumatic Principle". One study from Sweden, showing this, was published in 1994 [22]. Of 50 consecutive WAD patients, most had only minor symptoms at the first examination a week after the accident. Twenty-four patients had unchanged or increasing symptoms six to eight weeks after the initial examination. Thirteen of these 24 patients developed radiating arm symptoms during this time. Of the 24 patients, with unchanged or increasing symptoms six to eight weeks after the initial examination, four had similar problems, and five ( $21 \%)$ had greater problems five years after the accident compared with the problems after one year. The deterioration was due to disk injuries in several cases. Ten patients underwent surgery, and disk ruptures were detected in a third of these. Scar tissue was also noted after soft tissue injuries in the dorsal part of the cervical spine in several cases, although this was not observed on MR images. This study is important, because it proves that the deterioration in many patients was due to structural injuries of tissues, which cannot heal without sequelae.

A follow-up study from England, including 50 patients, showed that nine of 15 patients, who improved between three months and one year after the accident, deteriorated to their previous status, or worse, between one and two years [23]. A later study demonstrated a $28 \%$ deterioration rate between 10 and 15 years after the accident [24].

In a prospective one-year follow-up study in Sweden, which included less severely injured car occupants, 15 of 125 
cases (12\%) deteriorated during the first year [9]. Thus, there is clear evidence that WAD can deteriorate after an initial improvement.

There is another circumstance, which can explain deviations from the "Traumatic principle". It is related to the properties of the nervous system. Pain signals are relayed from receptors in injured tissue. They are transmitted by pain fibers to the spinal cord, like the fibers that convey tactile (sensory) information and proprioception (relative position of body parts). Pain signals are processed and integrated in the spinal cord before they are linked to higher centers of the central nervous system (CNS) and the cerebral cortex, where they are perceived to enable protection. The injurious event can also cause stress, anxiety and fear, which are processed in the more primitive parts of the CNS.

Many WAD patients have generalized hypersensitivity to pressure and reduced thresholds for heat. This can be explained by interference of the nerve signal transmission [25-29]. Widespread reduction of the thresholds for electrical stimulation and pressure of the finger at specific body part after whiplash trauma indicate changes in the central nervous system's regulation of pain signals [30-33]. Increased sensitivity to pain (hyperalgesi) and greater spread of referred pain have been reported for WAD patients as compared to others [34]. These studies, documenting both the increased incidence of local and referred pain, provide clinical support to the emergence of a new kind of transmission of sensory signals and altered pain pathways in the CNS after whiplash trauma. Pain signals can thus be enhanced by changes in upward and downward path system in the CNS - so called central disturbed pain modulation.

Pain is therefore not only the result of the pain system being "turned on" by a peripheral injury or pathologic process. Instead, pain reflects the excitability of nociceptive circuits. The excitability increases by changes in connections between nerve cells, which are triggered and preserved by the inflow of pain signals, leading to a change of the pain system's sensitivity. Normally, non-painful signals can activate the pain system in several ways, so that pain responses increase in amplitude, extend over time, and spread to areas without demonstrable pathology. Such changes characterize central sensitisation, and extensive experimental data and clinical studies over the last twenty years have shown that central sensitisation is a vital part of hypersensitivity to pain in many patients.

Although considerable progress has been made to sort out cellular and molecular mechanisms of central sensitisation, there is still much to learn, in particular about genetic and environmental factors. In addition, what triggers and maintains this phenomenon, and what are the specific factors that cause chronicity in some individuals? Some mechanisms are not sufficiently clarified, why diagnosis and treatment options are limited. These uncertainties are almost always referred to as a proof that central sensitization cannot explain deterioration in WAD patients, and the explanation model has been described as hypothetical by medical advisors of insurance companies. However, the phenomenon is well described in the literature since the 1990-ies, characterized by well-defined criteria, and thus cannot be dismissed at a determination of causality.

\section{The time interval between the accident and the symp- tom appearance}

Injury symptoms usually start within seconds. Sometimes, they are not noticed from the beginning, especially if other and more obvious or life-threatening injuries have occurred, like head or brain injuries with unconsciousness. There is no time limit, established by scientific methods, for the maximum delay until injury symptoms will appear. The rule of 72 hours has been claimed many times. Although the injury symptoms will start within this time in most cases, this limit is not absolute for all symptoms, because symptoms due to certain injuries will not emerge during the acute phase. A stretch of the brachial plexus may cause disturbances of the nerve signal transmission, with paresthesia and numbness in the arm and the fingers during the acute phase. If there is also a bleeding along the nerve sleeves, other or more pronounced nerve symptoms may occur later (weeks or months) due to secondary scar tissue (fibrosis).

The perceived pain from an injury depends on several factors. The psychological reactions to the accident are important. Individuals who experience great stress after an accident do not perceive pain like others. Many WAD patients refrain from ambulance transport, because the neck do not hurt so much. However, most of them visit the emergency department some days later with increased pain. Others do not search medical care until weeks or months later, because they have been told that WAD will decline within weeks or months, and that no treatment exists that speeds up recovery. Most people go to work, also with some pain. But WAD problems might increase after weeks or months, especially if they cause cognitive problems and sleeping disorders.

\section{Variation of symptoms with time}

The "Traumatic Principle" also implies that injury problems cannot vary with time. The previous example (1c, knee injury) disproves that. In fact, some patients with WAD or knee injuries experience great variation of symptom intensity. This is because pain depends on several factors, i.e. loading conditions of the injured body part. They usually are less pronounced during periods of small loads and greater other times.

There are also other factors, which influence pain development. Changes of the central nervous system (as described above) may explain varying and increasing pain by time. Pain is a subjective perception, and the magnitude of one person's pain cannot easily be compared to that of another. Pain intensity might be used to compare pain from time to time for a specific person, if all other factors are equal. This is seldom the case, as pain intensity also depends on mental factors. There is quite a strong relation between the duration and the intensity of post-traumatic pain, on one hand, and stress, anxiety, and depression, on the other $[35,36]$. This does not mean that there is a causal relationship between mental factors 
and the disposition to develop post traumatic pain. While such factors might amplify pain perception, they do not cause them. More important is that these connections make it possible to identify individuals, who are likely to develop chronic pain and need help. However, this is almost never done. Even worse is that people may interpret the relationship as if the problems are caused by the victim's mental disposition.

\section{There must not be a more likely explanations for the symptoms}

Neck pain and discomfort can arise for several reasons. Some are uncommon, like tumors or infections. Processes related to aging of the spine are more common. Spinal pain can arise from degenerative processes of intervertebral disks and facet joints. Neck pain is a common health problem, and a great majority of the population sometimes experience neck pain. The one-year prevalence of neck pain in the world population ranged from $16.7 \%$ to $75.1 \%$, with a mean of $37.2 \%$, according to a systematic review by Fejer et al. [37]. Specification of pain scores was made only in one of the 56 included studies ("substantial back, neck or shoulder problem ... in the previous year, restricting normal activities for more than one week") [38]. The age-standardized 6-month prevalence for significantly disabling neck pain was $4.6 \%$ according to a population-based cohort study in Sascatchewan adults in 1995-1996 according to Côté et al. [39].

However, prevalence data are not enough to decide if a person's neck pain is caused by an accident or has another origin. To do this, one must consider how often neck pain emerges spontaneously within a time period, and how often pain develops and remains after an injury. This means, one has to study the incidence of neck pain of different grades. Very few have done that.

The incidence of non-trauma-related neck pain was reported by Côté et al. [40]. The following symptom grades were used:

o No pain.

I Pain of low intensity and few activity limitations.

II Pain of high intensity, but few activity limitations

III Pain associated with high levels of disability and moderate limitations of activity.

IV Pain with high levels of disability and several activity limitations.

The number of cases with severe pain (grade III or IV) was too small, why these categories were added to one category: "disabling pain". Table 1 shows the one-year incidence of neck pain of specified grades for men and women in individuals who had not experienced any neck pain or disability in the previous six months.

According to table 1, the likelihood for an individual in this cohort to suffer from neck pain of any grade in the first year can be estimated to $10 \%$ for men and about $17 \%$ for women.
The vast majority developed mild (grade I) or moderate (grade II) pain. About one percent of men and a half percent of women developed disabling pain during one year.

To judge if a person's neck pain at a time after a whiplash trauma (i.e. one year) is caused by the trauma or not, one must compare the likelihood that the whiplash pain will remain at that time with the likelihood that pain would emerge within this time for some other reason.

The prognosis of WAD varies considerably according to the literature. The Swedish Whiplash Commission noted that about five to ten percent of WAD patients will develop significant chronic pain [41]. These percentages and those presented in table 1 make it possible to assess if the whiplash trauma or something else is the most probable cause (Appendix).

\section{Discussion}

Medical judgments should be based on scientific evidence and proven experience. The major obstacle that prevents a correct assessments of the relationship between an accident and its consequence is lack of knowledge. This lack relates to the accident itself, the injuries caused by the accident, the associated symptoms, their development, and their impact on the ability to work. This means disciplines, which are not familiar to many, like biomechanics and forensic medicine. Uncertainty about how causality is to be assessed regarding inconvenience after traffic accidents has led to the establishment of a specific discipline - forensic biomechanics. The term has been used more frequently since it was presented in 2005 [42]. The Journal of Forensic Biomechanics has monitored the subject since 2010 [43].

Legal disputes about the causal link between an accident and later medical problems often involve medical representatives of the injured person and medical advisors to the insurance company. It is natural that treating physicians will support their patients, because medical treatment is based upon trust. Doctors hired by insurance companies can be tempted to assess an injury claim to the insurance company's benefit as this benefits the company and the doctor's continued involvement with the company. Thus, there is a risk of undue loyalty for both the medical expert of the injured person and the insurance company's medical advisor. There may also be ignorance of facts in both groups, which could be explained by unhealthy loyalty to established opinions that have existed for a long time. Both categories should consider what causality means and what conditions apply when assessing the cause of an inconvenience after a traffic accident. Also society institutions need to know what matters in disputes about relationships in these matters.

Table 1: The one-year incidence of spontaneous pain of specified grades for men and women, according to Coté et al. [40]

\begin{tabular}{|c|c|c|c|c|}
\hline & \multicolumn{2}{|c|}{ Men (n=271) } & \multicolumn{2}{|c|}{ Women (n=242) } \\
\hline Grade of pain & $\%$ & $(95 \% \mathrm{Cl})$ & $\%$ & $(95 \% \mathrm{Cl})$ \\
\hline I-IV (any grade) & 10 & $(6.4-13.5)$ & 16.9 & $(12.2-21.7)$ \\
\hline I & 7 & $(4.0-10.0)$ & 16.1 & $(11.5-20.7)$ \\
\hline II & 1.8 & $(0.6-4.2)$ & 0.4 & $(0.0-2.3)$ \\
\hline III-IV (disabling) & 1.1 & $(0.2-3.2)$ & 0.4 & $(0.0-2.3)$ \\
\hline
\end{tabular}


Biomechanics is the study of the mechanical structures and the function of biological systems. Impact biomechanics is a subgroup that analyzes what happens in the body during a collision. Forensic medicine is a science that apply medical knowledge to answer specific questions of law, like the cause of an injury. Forensic biomechanics - a branch of forensic medicine - has evolved during the last decade. So far, this discipline has mostly been used by insurance companies in lawsuits in order to dispute the plaintiff's' arguments of causality. However, the same knowledge can be used by the plaintiff in order to proof causality.

The biomechanical literature has not yet defined the outer limits of what loads a human body can tolerate. Nor has it defined the lower limits. In fact, this is impossible, because all humans are different, and every accident has unique determinants. Besides, the injury limit cannot be specified for every possible load. Therefore, causality can only be determined in relative terms. This means one must compare the probability of every possible explanation for the outcome.

The criterion 1a implies that bodily injury may be caused by the event. It does not imply that an injury must occur in all similar events. Biologic plausibility only pertains to whether an outcome can possibly result from an exposure, and is unrelated to the rate or frequency of the outcome. Evidence of low incidence is not evidence of biologic implausibility. People who underestimate or deny the risk of injury in low energy impacts often refer to experimental tests and selected studies on real accidents.

There are several reasons why experimental tests cannot be used to establish injury thresholds. The first is logical: it is not possible to define thresholds for zero risk. Another reason is that people injured in real car crashes are more vulnerable than those taking part in various experimental tests. Car occupants sitting posture are seldom perfect, so they are often exposed to asymmetric loads. Furthermore, factors like degenerative spinal changes increase the vulnerability.

Thus, it is reasonable to argue that the risk of injury is low below a certain limit, but it is not zero. In fact, there is important differences between simulated collisions in experimental tests and real accidents. The impact direction, the occupant's posture during the crash and his/her pathophysiological characteristics are also important. According to basic mechanical laws, an asymmetrical load will cause a more unfavorable stress/strain distribution in the spine than a symmetric one. Thus, collisions that are not pure rear or frontal entail a greater injury risk, like rear or frontal collisions do when the occupant's head is turned.

Many attempts have been made to prove that chronic WAD very seldom results from car crashes, the most notorious perhaps being a study from Lithuania, published in The Lancet by Schrader et al. [44]. That study received justified criticism by several scientists [45]. It was too small and it was based on accidents reported by police, not on those who sought medical advice after the accident. It could not possibly discover differences between the outcome for injured car occupants and controls. A similar investigation by the same group also failed to demonstrate such a difference for the same reasons [46].

Another group published an interesting experimental study on "placebo rear-end collisions" in 2001 [47]. In fact, there was no collision. The vehicle was just released on an inclined ramp when a crash noise was heard. About $20 \%$ of the subjects reported neck symptoms after the "crash", and most of these showed greater emotional instability according to the Freiburger Personality Inventory. This study has be taken as a proof that minor collisions cannot cause WAD. However, it is rather evidence that minor collisions may cause symptoms, because "placebo" collisions can. And - what is more important - some people are more vulnerable because of factors that increase the injury risk like degenerative changes of the spine and/or psychological characteristics.

The criterion $1 \mathrm{~b}$ relates to the sensitivity of diagnostic methods, which normally means radiological investigations. As was shown in the study by Jónsson et al. [17], minor skeletal injuries are very seldom detected. Thus, it is almost impossible to exclude them. One other and important reason is that CT and MRI scans are taken with the patient in the lying position. Instability due to ligament injuries between adjacent vertebrae is more difficult to detect in the lying position, because the influence of gravity is reduced. There are methods and technique for examination of the body in the erect position, but these are used only in a few countries. So far, such upright examinations are not accepted by many. This is difficult to understand, because a disk protrusion or bony spur that impinges on a nerve root or the spinal cord in the upright position but not supine would give important information. This is a problem not only for medical advisors of insurance companies but also for the medical profession.

The criterion $1 \mathrm{c}$ implies that the symptoms after the trauma must be a biologically possible or reasonable (plausible) consequence of the trauma. Reasonable or plausible means more or less likely, but not impossible. One unexpected case is enough to disprove the impossible. The difficulty is to estimate the probability for such a consequence for each possible cause.

This means that symptoms that deviate from the "Traumatic Principle" should not always be judged as if they were not caused by a trauma. If so, all who develop increasing or varying pain after an initial peak would be disqualified. The term plausible is misleading, as it might implicate that deviation from the most plausible or probable course should prove an alternate explanation. WAD symptoms vary by time, and some may increase due to factors described above.

The criterion 2a implies that symptoms must start within a few days. It is usually so, and many patients seek medical care within hours because they feel some pain and stiffness in the neck. In most cases, no objective signs of injury are documented that require further medical investigations, and a good prognosis is assured. Next day, the victim often awakes with a stiff neck and headache. This is not surprising, since the muscular response to whiplash injury does not occur until several hours later. Hopefully, this was explained at the initial 
medical examination, but many patients do not remember all details in the acute stage.

The criterion $2 \mathrm{~b}$ has mostly been strictly interpreted, i.e. injury symptoms decrease continuously after an initial maximum. This is also the typical pattern for the major part with minor symptoms - perhaps $90 \%$. These cases almost never provide any difficulties. The other $10 \%$, with varying or increasing symptoms, often face considerable difficulties when they are judged by the medical advisors of insurance companies. These advisors often refer to the "Traumatic Principle" as if a deviant development never would occur after an injury. However, one must realize that this principle only refers to the mean or median value by time for all injured - not for a specific case. In fact, the development of post traumatic pain varies between each individual. If this is not recognized, many WAD patients will be misjudged, perhaps all these $10 \%$.

The criterion 3 implies that there must not be any more likely other explanation of the symptoms. There are several possible other explanations like rheumatoid arthritis, tumors, infections, etcetera, but they are rare. In most cases, the cause is unknown, or attributed to degenerative changes. This is not surprising, because spinal pain is common as well as degenerative changes.

The bone and joint decade 2000-2010 task force on neck pain and its associated disorders identified 469 studies on incidence and risk factors for neck pain [48]. Nine of these were rated as scientifically admissible for inclusion in a best evidence synthesis, regarding incidence rates for neck pain in the general population $[40,49-56]$. According to these, the one year incidence for activity-limiting neck pain ranged from $1.7 \%$ to $11,5 \%$. There were variations in population, setting, inclusion/exclusion criteria, method of ascertainment, and case definition. The study by Côté et al., [40] is the only one that investigated the incidence of neck pain of disabling pain in the general population. A similar study has not been published so far.

Degenerative spinal changes may impinge on nerve roots or the spinal cord and cause various symptoms like rhizopathy and weakness. If they don't affect nerve tissue they quite seldom cause severe pain, however. More often, they cause stiffness and reduced mobility of the affected spinal segments.

Degenerative spinal disorders are often considered to be the cause of neck pain following an accident. This might be true, but there are some important circumstances and conditions which should be clarified before such a conclusion is made. One has to consider and answer the following questions. The first can be divided in two parts.

1. Are there reasonable grounds to believe that degenerative changes increase the risk of problems after a whiplash trauma?

a. Can degenerative changes increase the risk of injury?

b. Can degenerative changes increase the risk of late symptoms after an injury?
2. Would the neck pain emerge without the accident?

The answer to I. a. is yes. This is so, because degenerative changes of spinal elements make these more vulnerable, as degenerative changes do for joints in other parts of the body like the knee. Degenerative changes of vertebral disks and intervertebral joints also make them less resilient to external loads and less mobile, and this will reduce the amount of energy that can be absorbed.

There is also an increased risk of injury to nerve tissue close to degenerated structures, like nerve roots passing through the intervertebral foramina, encroached by bone spurs from uncovertebral and intervertebral joints.

The answer to I. b. is also yes. Degeneration of joint cartilage can also change the pattern of movement of joints and cause instability due to ligament laxity until the stabilizing process of degeneration has compensated for this. There is also other possibilities, i.e. bleeding around nerve sleeves after a great stretch of the brachial plexus.

Question II is often answered with yes by medical advisors of insurance companies. Perhaps this is because they do not understand or deny what follows from statistical analyses. This is explained in more detail in the appendix, which also contains some examples.

\section{Final Remarks and Conclusions}

To determine causality can be difficult, even for the skilled. Paradoxical relationships between the crash severity and the injury risk hamper the assessment. No limit can be assessed, below which an injury cannot occur. Diagnostic tools are too crude for minor injuries that may cause symptoms later. Variation of symptoms, depending on valid factors that are rarely taken into account is a rule in WAD patients seeking compensation. Degenerative changes are often given as an explanation for the final condition. In fact, such changes will increase the injury risk, but this is not recognized. Causality should be based on correct analyses. Proof should not be based on studies that deny that WAD is a reality.

These circumstances should bring attention to the difficulties that WAD patients face in health care and insurance evaluations. Hopefully, knowledge, understanding, and acceptance will solve the dilemma these victims have experienced since a long time.

\section{Appendix}

The probability for an event to occur is denoted by P. P may take any value from o (cannot happen) to 1 (will always happen). Let us denote the probability for an individual to develop chronic pain after a whiplash trauma $\mathrm{P}(\mathrm{WAD})$. This can be compared with the probability for an individual, who has not been injured, to have similar problems for another reason, e.g. degenerative changes. Let us denote this $\mathrm{P}($ not WAD). That $\mathrm{P}($ not $\mathrm{WAD})$ is greater than $\mathrm{P}(\mathrm{WAD})$ does not mean that the neck problems occurred for another reason. 
It is important to distinguish between probability and causality. In assessments of causality, the probability for explanation A might be compared with the probability for explanation B. One common mistake, when trying to estimate causation, is to use raw prevalence or incidence data, i.e. to compare the occurrence or appearance of residual pain after a whiplash trauma with that of spontaneous neck pain in the population. The following example shows what could happen if these entities are not used correctly.

\section{Example 1: The mistake of comparing probabilities and not conditional probabilities.}

\section{Comparing probabilities}

Explanation A. Neck pain after a traffic accident: About 19000 persons reported neck problems after road traffic accidents in Sweden (almost 10 million inhabitants) in 2008. Thus, the probability for a randomly selected person in Sweden to have neck problems after a road traffic accident can be estimated to 19000 of 10 million, or approximately 0.002 per year.

Explanation B. Spontaneous neck pain: About $80 \%$ of the population will suffer from neck or back problems at some point in life [57]. Let us assume that one third will have neck problems, life expectancy is 80 years, neck symptoms are very rare before the age of 20 , and the incidence per year is constant. The probability for a randomly selected individual, between 20 and 80 years of age, to suffer from neck disorders during the following year can then be estimated to

$(80 / 100) *(1 / 3) * 1 /(80-20) \approx 0.004$.

If we compare these two probabilities (0.002 and 0.004$)$ we find that the probability for degenerative neck disorders is twice as great as that for neck problems after a traffic accident. This leads to the conclusion that a car accident is less likely a cause of neck problems than age-related changes.

The conclusion is wrong, because the choice is not random when we want to determine if some person will have neck problems one year after a car accident. We have a person who sustained neck problems at the accident, i.e. we have a particular condition.

Instead, we must compare the probability for this particular individual to suffer from long-standing problems after a traffic accident, with the likelihood that the symptoms are due to something else, for example age-related degenerative changes. This will be shown in the following example.

\section{Comparing conditional probabilities}

The great majority of individuals who report initial neck pain after a whiplash trauma will recover completely within a few months, and 5-10\% will have permanent neck problems [41]. We assume that $5 \%$ will have permanent problems after one year. Thus, out of 1000 individuals, who report initial neck problems after a car accident, 50 will have permanent problems, and 950 will not.

Out of 1000 individuals, who have been exposed to a whiplash mechanism in a car crash without injury, some will have neck problems within one year due to degenerative changes and not to the accident, like those who have not been involved in an accident. We assume that this probability is the same as in the previous example, i.e. 0.004.

In order to assess whether the neck problems after a year is due to an accident or not, the following analysis should be made. Table 2 illustrates the distribution of 2000 persons who had been exposed to a whiplash mechanism. Half of them had initial neck symptoms. The other half had no initial symptoms, but they developed neck pain due to other causes, like degenerative changes, within a year.

Column $\mathrm{P}$ (conditional probability) shows an estimate of the probability for neck problems after a year in the two groups. $\mathrm{P}(\mathrm{B} / \mathrm{A})$ is the conditional probability for an individual to have neck problems after a year, provided that there were initial neck symptoms. $\mathrm{P}(\mathrm{B} / \operatorname{not} \mathrm{A})$ is the conditional probability for an individual to have neck problems after a year for other reasons, for example degenerative changes, provided that no neck symptoms were noted at the accident.

When comparing the conditional probabilities $\mathrm{P}(\mathrm{B} / \mathrm{A})$ and $\mathrm{P}(\mathrm{B} /$ not $\mathrm{A})$, we find that neck problems after a year in those who had initial neck symptoms is much more likely $(\mathrm{P}=0.050)$ compared with those without initial neck problems $(\mathrm{P}=0.004)$. The ratio of these two numbers is 12.5 . This means that for individuals, with initial neck symptoms that persist one year later, the accident is 12.5 times more likely the cause than other causes.

\section{Example 2: A diagnostic code problem}

A woman, 40 years old, sustained a whiplash trauma in a car accident. Her previous medical history was unremarkable, although she had suffered from neck pain for some weeks three years earlier. The initial radiographs showed no signs of injury, only moderate degenerative changes between the sixth and seventh vertebrae ( 6 6- 7 7), with a bulging disk constricting the right intervertebral foramen. She was on sick leave for two months after the accident and returned to work after that, in spite of some residual pain. She managed to work for almost ten months, but the neck pain got worse during periods, and sometimes there were also radiating pain and numbness in the right arm and the middle fingers. Finally she could not work at all. What diagnosis would you enter on the sick note as her physician one year after the accident?

The physician has two options (at least). One is the diagnosis codes for WAD (a cervico-brachial syndrome in this case), due to the accident one year earlier (M53.1; T91.8; S13.4; V43.5). The second is the diagnosis code for nerve root symptoms caused

Table 2: Estimation of probabilities for neck problems after a whiplash trauma for those with and those without initial neck symptoms.

\begin{tabular}{l|l|l|l|l|l|}
\hline \multirow{2}{*}{$\begin{array}{l}\text { Exposed to a whiplash trauma } \\
\text { with initial neck symptoms } \\
\text { (A) }\end{array}$} & $\begin{array}{l}\text { Residual neck symptoms } \\
\text { after one year (B) }\end{array}$ & \multicolumn{2}{l}{$\begin{array}{l}\text { P(contitional } \\
\text { probability) }\end{array}$} \\
\cline { 2 - 6 } & No (not B) & Yes (B) & Total & Value & Designation \\
\hline Yes (A) & 950 & 50 & 1000 & 0,050 & P(B/A) \\
\hline No (not A) & 996 & 4 & 1000 & 0,004 & P(B/not A) \\
\hline Total & 1946 & 54 & 2000 & 0,027 & \\
\hline
\end{tabular}


by degenerative changes of the cervical disk, without reference to a previous injury (M50.1). This makes a clear difference. The first diagnoses carry a right to full compensation, but not the other one. Further, and more serious is that the insurance company may use the second diagnosis as a proof that her inability to work after one year is not caused by the accident.

What could be made to justify the first diagnosis (WAD) before the other (nerve dysfunction because of a degenerative process of the cervical spine)? For those, who know the patient's history well and who arranges for thorough follow-ups during the first months, the risk of misjudgment is low. For other, the choice is more random, but the information presented in the previous paragraph can be used as a guidance.

On one hand; the probability that a person, injured in a whiplash trauma, will suffer from disabling pain one year later is $5-10 \%$. Women have a worse prognosis. Therefore, the probability that a women will suffer from disabling pain one year after a whiplash trauma is at least $5 \%$. On the other hand; the probability that a woman will suffer from disabling neck pain, which emerged during one year, without a specific reason is maximum $0.4 \%$ (Table 1 ). By just comparing these probabilities, we can conclude that the accident is more likely the cause of pain than the degenerative process of the C6-C7 disk. The accident is at least ten times more probable, if no other factors are considered. Are there any other factors? What would be the case if the disk degeneration was in progress at the time of accident?

There is no obvious answer to that question, based on the information given so far. However, there is evidence that spinal degenerative changes, visible on radiographs, are usually not related to spinal pain [57]. There is also evidence that degenerative changes increase the vulnerability of involved and adjacent structures [58]. In addition, the study [9], demonstrated a significant relationship between the incidence of degenerative changes constricting root canals, and the development of whiplash related disorders with neurological signs. There is also evidence that degenerative changes occur significantly more frequently in patients who had sustained soft tissue injuries than in a control population [11].

These circumstances all indicate that the accident caused the injury and the later problems in this example. The complete diagnostic codes should be M53.1; T91.8; S13.4; V43.5.

\section{Example 3: The Lithuanian studies}

The incidence of chronic neck pain (defined as neck pain more than seven days per month) was $8.4 \%$, one to three years after car collisions according to the Lithuanian study [44]. The incidence of chronic neck pain for the controls was $6.9 \%$. The difference was not statistically significant, so the authors concluded that there was no difference between injured subjects and controls. The figures are interesting, as they are quite similar to those presented by Côté et al. in the Sascatchewan study [40]. In that study, the spontaneous one year neck pain incidence for men/women, respectively, were 10 $\% / 17 \%$ for neck pain of "any grade", $7 \% / 16 \%$ for neck pain of "grade I", and $1.8 \% / 0.4 \%$ for neck pain of "grade II". Thus, the incidence of neck pain (without reference to the cause) in Lithuania looks like the incidence of spontaneous neck pain in Sascatchewan. And that is what it should be, according to the criticism that followed [45].

In order to compare the probability for residual pain a certain time after a neck injury with the probability for spontaneous neck pain in a population, one must use subjects with neck injuries that may lead to prolonged problems. A way of doing this is to study those who seek medical care for the injury. In Göteborg, Sweden, that group was just about five percent of all car occupants involved in car accidents with or without neck complaints after the event [59]. Of these five percent, only one tenth developed chronic neck problems. Another Swedish study [60], which included two control groups, showed almost a three-fold risk for residual neck-shoulder problems seven years after a rear-end impact compared with people not involved in car accidents. So, if Schrader et al. [44], wanted to study the prognosis of WAD, they should have used a ten times greater cohort. They did the same mistake in their later study [46].

\section{References}

1. Hill $A B$ (1965) The environment and disease: association or causation? Proceedings of the Royal Society of Medicine. Proc R Soc Med 58: 295-300. Link: https://goo.gl/TYmziE

2. Kundi M (2006) Causality and the interpretation of epidemiologic evidence Environ Health Perspect 114: 969-974. Link: https://goo.gl/8eG3pk

3. Freeman MD, Rossignol AC, Hand ML (2008) Forensic epidemiology: a systematic approach to probabilistic determination in disputed matters. Forensic Legal Med 15: 281-290. Link: https://goo.gl//p3IMw

4. Freeman MD, Centeno CJ, Kohles SS (2009) A systematic approach to clinical determinations of causation in symptomatic spinal disk injury following motor vehicle crash trauma. PM R 1: 951-956. Link: https://goo.gl/Z5S760

5. Castro WH, Schilgen M, Meyer S, Weber M, Peuker C, et al. (1997) Do "whiplash injuries" occur in low-speed rear impacts? Eur Spine J 6: 366-375. Link: https://goo.gl/WZMfoh

6. Ewans RW (1992) Some observations on whiplash injuries. Neurol Clin 10 975-997. Link: https://goo.gl/WZgZOJ

7. Huber A, Beran H, Trenkler J, Hager A, Witzman A, et al. (1993) Whiplash injury of the cervical spine from neurosurgical, traumatological and psychological aspects. Neurochirurgia 36: 51-55. Link: https://goo.gl/zdMa2x

8. Miles KA, Maimaris C, Finlay D, Barnes MR (1998) The incidence and prognostic significance of radiological abnormalities in soft tissue injuries to the cervical spine. Skeletal Radiol 17: 493-496. Link https://goo.gl/uw07VA

9. Bunketorp O, Jakobsson L, Norin H (2004) Comparision of frontal and rear-end impacts for car occupants with whiplash-associated disorders: Symptoms and clinical findings. 2004 International IRCOBI Conference on the Biomechanics of Impacts 245-256. Link: https://goo.gl/xRUW5H

10. Workman J, Thambyah A, Broom N (2017) The influence of early degenerative changes on the vulnerability of articular cartilage to impact-induced injury. Clin Biomech 43: 40-49. Link: https://goo.gl/W0999q

11. Watkinson A, Gargan MF, Bannister GC (1991) Prognostic factors in soft tissue injuries of the cervical spine. Injury 22: 307-309. Link https://goo.gl/Br739i 
12. Hamer AJ, Gargan MF, Bannister GC, Nelson RJ (1993) Whiplash injury and surgically treated cervical disc disease. Injury 24: 549-550. Link: https://goo.gl/1yWgOh

13. Guez M, Hildingsson C, Stegmayr B, Toolanen G (2003) Chronic neck pain of traumatic and non-traumatic origin. Acta Orthop Scand 74: 576-579. Link https://goo.gl/mS712n

14. Bunketorp L, Stener-Victorin E, Carlsson J (2005) Neck pain and disability following motor vehicle accidents - a cohort study. Eur Spine J 14: 84-89. Link: https://goo.gl/J4bejm

15. Kullgren A, Krafft M (2008) Influence of change of velocity and acceleration on whiplash injury risk: results from real-world crashes. Paper presented at the $2^{\text {nd }}$ Int. Conf. on Neck Injuries in Road Traffic and Prevention Strategies, Nov 18-19, Munic, Germany (TUV SUD Akademie GmbH).

16. Holmes JF, Akkinepalli R (2005) Computed Tomography Versus Plain Radiography to Screen for Cervical Spine Injury: A Meta-Analysis. J Trauma 58: 902-905. Link: https://goo.gl/54IIA6

17. Jónsson H Jr, Bring G, Rauschning W, Sahlstedt B (1991) Hidden cervical spine injuries in traffic accident victims with skull fractures. J Spinal Disord 3: 251-263. Link: https://goo.gl/PiyBh6

18. Urenholt L, Grunnet-Nilsson N, Hartvigsen J (2002) Cervical Spine Lesions after Road Traffic Accidents. A systematic review. Spine 27: 1934-1941. Link: https://goo.gl/jf3KZl

19. Taylor JR, Twomey LT (1993) Acute injuries to cervical joints: an autopsy study of neck sprains. Spine 18: 1115-1122. Link: https://goo.gl/eUlkFt

20. Taylor JR, Taylor MM (1996) Cervical spinal injuries: an autopsy study of 109 blunt injuries. J Musculoskeletal Pain 4: 61-79. Link: https://goo.gl/YKI2kw

21. (2006) The National Board of Health and Welfare. Stockholm, 2006-10-02 (SoS Dnr 441-323/06).

22. Jónsson H, Cesarini K, Sahlstedt K, Rauschning W (1994) Findings and Outcome in Whiplash-Type Neck Distortions. Spine 19: 2733-2743. Link: https://goo.gl/fa3rSN

23. Gargan MF, Bannister GC (1994) The rate of recovery following whiplash injury. Eur Spine J 3: 162-164. Link: https://goo.gl/loQ2EH

24. Squires B, Gargan MF, Bannister GC (1996) Soft-tissue injuries of the cervical spine. 15-year follow-up. J Bone Joint Surg Br 78: 955-957. Link: https://goo.gl/Tv9trZ

25. Greening J, Dilley AL, Lynn B (2005) In vivo Study of Nerve Movement and Mechanosensitivity of the Median Nerve in Whiplash and Non-specific Arm Pain Patients. Pain 115: 248-253. Link: https://goo.gl/Ucqtfr

26. Kasch H, Stengaard-Pedersen K, Arendt-Nielsen L, Staehelin Jensen $T$ (2001) Headache, Neck Pain, and Neck Mobility after Acute Whiplash Injury: A Prospective Study. Spine 26: 1246-1251. Link: https://goo.gl/Skg7om

27. Scott D, Jull G, Sterling M (2005) Widespread Sensory Hypersensitivity Is a Feature of Chronic Whiplash-Associated Disorder but Not Chronic Idiopathic Neck Pain. Clin J Pain 21: 175-181. Link: https://goo.gl/FRnJo5

28. Sterling M, Jull G, Vicenzino B, Kenardy J (2003) Sensory Hypersensitivity Occurs Soon after Whiplash Injury and Is Associated with Poor Recovery. Pain 104: 509-517. Link: https://goo.gl/Q910s2

29. Sterner Y, Toolanen G, Knibestol M, Gerdle B, Hidingsson C (2001) Prospective Study of Trigeminal Sensibility after Whiplash Trauma. J. Spinal Disord 14: 479-486. Link: https://goo.gl/liif6e

30. Banic B, Petersen-Felix S, Andersen O, Radanov B, Villiger P, et al. (2004) Evidence for Spinal Cord Hypersensitivity in Chronic Pain after Whiplash Injury and in Fibromyalgia. Pain 107: 7-15. Link: https://goo.gl/6qSKEj
31. Curatolo M, Petersen-Felix S, Arendt-Nielsen L, Giana C, Zbinden AM, et al. (2001) Central Hypersensitivity in Chronic Painafter Whiplash Injury. Clin J Pain 17: 306-315. Link: https://goo.gl/EfHMXL

32. Kasch H, Stengaard-Pedersen K, Arendt-Nielsen L, Staehelin Jensen T (2001) Pain Thresholds and Tenderness in Neck and Head Following Acute Whiplash Injury: A Prospective Study. Cephalgia 21: 189-197. Link: https://goo.gl/dAsqPg

33. Koelbaek Johansen M, Graven-Nielsen T, Schou Olesen A, Arendt-Nielsen L (1999) Generalised Muscular Hyperalgesia in Chronic Whiplash Syndrome. Pain 83: 229-234. Link: https://goo.gl/IZRIIQ

34. Passatore M, Roatta S (2006) Influence of sympathetic nervous system on sensorimotor function: whiplash associated disorders (WAD) as a model. Eur J Appl Physiol 98: 423-449. Link: https://goo.gl/lt7CB2

35. Drottning M, Staff PH, Levin, Ulrik Fr Malt (1995) Acute emotional response to common whiplash predicts subsequent pain complaints: a prospective study of 107 subjects sustaining whiplash injury. Nord J Psychiatry 49: 293299. Link: https://goo.gl/pAhX1a

36. Olsson I, Bunketorp O, Carlsson SG, Styf J (2002) Prediction of outcome in whiplash-associated disorders using West Haven-Yale Mulitdimensional Pain Inventory. European Journal of Pain 13: 760-768. Link: https://goo.gl/C9AUSs

37. Fejer R, Ohm Kyvik K, Hartvigsen J (2006) The prevalence of neck pain in the world population: a systemtic critical review of the literature. European Spine J 15: 834-848. Link: https://goo.gl/cxFo5Y

38. Lock C, Allgar V, Jones K, Marples G, Chandler C, et al. (1999) Prevalence of back, neck and shoulder problems in the inner city: implications for the provision of physiotherapy services in primary healthcare. Physiother Res Int 4: 161-169. Link: https://goo.gl/WYkxsB

39. Côté P, Cassidy JD, Carroll L (1998) The Saskatchewan health and back pain survey: The prevalence of neck pain and related disability in Saskatchewan adults. Spine 23: 1689-1698. Link: https://goo.gl/3GdWXn

40. Côté $P$, Cassidy JD, Carrol LJ, Kristman V (2004) The annual incidence and course of neck pain in the general population: a population-based cohort study. Pain 112: 267-273. Link: https://goo.gl/1PXj1V

41. Jansen GB1, Edlund C, Grane P, Hildingsson C, Karlberg M (2008) Whiplash injuries: diagnosis and early management. The Swedish Society of Medicine and the Whiplash Commission Medical Task Force. Eur Spine J 3: 355-417. Link: https://goo.gl/hdMz7l

42. Schneck DJ (2005) Forensic biomechanics (Editorial). American Laboratory 37: 5-6.

43. Schneck DJ (2010) Welcome to a new journal. (Editorial). Journal of Forensic Biomechanics 1: 1

44. Schrader H, Obelieniene D, Bovim G, Surkiene D, Miseviciene D, et al. (1996) Natural evolution of late whiplash syndrome outside the medicolegal context. Lancet 347: 1207-1211. Link: https://goo.gl/fj2Fda

45. Michael D Freeman, Arthur C Croft (1996) Late whiplash syndrome. The Lancet 348: 124-125. Link: https://goo.gl/EFnECT

46. Obelieniene D, Schrader H, Bovim G, Miseviciene I, Sand T (1999) Pain after whiplash: a prospective controlled inception cohort study. J Neurol Neurosurg Psychiatry 66: 279-283. Link: https://goo.gl/UyWnPQ

47. Castro WH, Meyer SJ, Becke ME, Nentwig CG, Hein MF, et al. (2001) No stress - No whiplash? Prevalence of whiplash symptoms following exposure to a placebo rear-end collision. Int J Legal Med 114: 316-322. Link: https://goo.gl/c9QT03

48. Hogg-Johnsson S, van der Velde G, Carrol LJ, Holm LW, Cassidy JD, et al (2008) The burden and determinants of neck pain in the general population. Spine 33: S39-S51. Link: https://goo.gl/EC3Svj 
49. Björnstig U, Hildingsson C, Toolanen G (1990) Soft-tissue injury of the neck in a hospital based material. Scand J Soc Med 18: 263-267. Link: https://goo.gl/35id02

50. Bot SD, van der Waal JM, Terwee CB, van der Windt DA, Schellevis FG, et al. (2005) Incidence and prevalence of complaints of the neck and upper extremity in general practice. Ann Rheum Dis 64: 118-123. Link: https://goo.gl/Y3bvGx

51. Bring G, Björnstig U, Westman G (1996) Gender patterns in minor head and neck injuries: an analysis of casualty register data. Accid Anal Prev 28: 359369. Link: https://goo.gl/cptX72

52. Croft PR, Lewis M, Papageorgiou AC, Thomas E, Jayson MI, et al. (2001) Risk factors for neck pain: a longitudinal study in the general population. Pain 93 317-325. Link: https://goo.gl/68CUX9

53. Kondo K, Molgaard CA, Kurland LT, Onofrio BM (1981) Protruded intervertebral cervical disk: incidence and affected cervical level in Rochester, MN, 1950 through 1974. Minn Med 64: 751-753. Link: https://goo.gl/Yp2YTW

54. Rekola KE, Keinanen-Kiukaanniemi S, Takala J (1993) Use of primary health services in sparsely populated country districts by patients with musculoskeletal symptoms: consultations with a physician. J Epidemiol Community Health 47: 153-157. Link: https://goo.gl/78Kpsd
55. Ståhl M1, Mikkelsson M, Kautiainen H, Häkkinen A, Ylinen J, et al. (2004) Neck pain in adolescence. A 4-year follow-up of pain-free preadolescents. Pain 110: 427-431. Link: https://goo.gl/yUDqaE

56. Versteegen GJ, Kingma J, Meijler WJ, ten Duis HJ (1998) Neck sprain not arising from car accidents: a retrospective study covering 25 years. Eur Spine J 7: 201-205. Link: https://goo.gl/yYXjW2

57. (2000) SBU. Back and neck pain. Stockholm: Swedish Council on Health Technology Assessment in Health Care (SBU); 2000. SBU report no 145/1 (in Swedish). Link: https://goo.gl/uOCzrT

58. Tominaga Y, Maak TG, Ivancic PC, Panjabi MM, Cunningham BW (2006) Head-turned rear impact causing dynamic cervical intervertebral foramen narrowing: implications for ganglion and nerve root injury. J Neurosurg Spine 4: 380-387. Link: https://goo.gl/ya7VMn

59. Olsson I, Bunketorp O, Blåder S, Lindh M, Markhede G, et al. (1988) Nackbesvär efter bilolyckor. Proceedings, the Scientific Days of The Swedish National Road and Transport Research Institute. Linköping pp.111-26.

60. Berglund A, Alfredsson L, Cassidy JD, Jensen I, Nygren $\AA$ (2000) The association between exposure to a rear-end collision and future neck or shoulder pain: A cohort study. J Clin Epidemiology 53: 1089-1094. Link: https://goo.gl/fqVvLb

Copyright: ( 2017 Bunketorp O. This is an open-access article distributed under the terms of the Creative Commons Attribution License, which permits unrestricted use, distribution, and reproduction in any medium, provided the original author and source are credited. 